\title{
The Erosivity Potential of Common Paediatric Over-The-Counter Medications and its Reduction by Remineralising Agents
}

\section{Huang LL*, Chai L and Seow WK}

School of Dentistry, University of Queensland, Queensland, Australia

\begin{abstract}
Aim: The exposure of children's teeth to acidic medications poses a risk for dental erosion, yet the erosivity of paediatric medications has scarcely been reported. The present study investigated the erosive potential of paediatric over-the-counter (OTC) medications, and assessed the change of the erosive potential in the presence of remineralising agents.

Methods: A range of paediatric OTC medications and commercially available drinks was examined for $\mathrm{pH}$ and titratable acidity (TA). Detailed testings of $\mathrm{pH}$ and TA were investigated on representative drinks after addition of remineralising agents: Tooth Mousse ${ }^{\circledR}(T M)$, Tooth Mousse Plus ${ }^{\circledR}$ (TMP), Clinpro ${ }^{\mathrm{TM}}, 1.23 \%$ neutral sodium fluoride $(\mathrm{NaF})$, and artificial saliva (AS).

Results: Paediatric OTC medications exhibited $\mathrm{pH}$ values of less than 5.5 , which were comparable to commercial fruit juices and carbonated soft drinks. The TA values of OTC medications were similar to commerical fruit juices and carbonated soft drinks and ranged between $0.9 \mathrm{~mL}$ to $25.9 \mathrm{~mL} / 20 \mathrm{~mL}$ of $0.1 \mathrm{M}$ sodium hydroxide. In contrast, most dairy products, baby formulas, and bottled water had near-neutral $\mathrm{pH}$ (6.3-7.4) and low TA values of less than $1.3 \mathrm{~mL} /$ $20 \mathrm{~mL}$. The addition of TM, TMP, neutral NaF, and AS to the paediatric OTC medication increased the pH significantly compared to the control (Phosphate-buffered saline, PBS; $p<0.001$ ). The addition of TM, TMP, neutral NaF, and AS decreased the TA for paediatric OTC medication compared to the control (PBS; $p<0.001-p<0.05$ ), but not consistently.
\end{abstract}

Conclusions: Paediatric OTC medications have erosive potential comparable to commercially available drinks. The erosive parameters ( $\mathrm{pH}$ and TA) of paediatric OTC medications can be modified by the addition of TM, TMP, neutral $\mathrm{NaF}$ and artificial saliva, but not Clinpro ${ }^{\mathrm{TM}}$.

\section{Keywords: Dental erosion; Medications; Children; Remineralisation}

Abbreviations: OTC: Over-the-counter; TA: Titratable acidity; TM: Tooth Mousse ${ }^{\oplus}$; TMP: Tooth Mousse Plus ${ }^{\oplus}$; NaF: Sodium fluoride; CPP-ACP: Casein phosphopeptide-amorphous calcium phosphate; PBS: Phosphate-buffered saline; AS: Artificial saliva

\section{Introduction}

Dental erosion is a form of irreversible non-carious tooth loss, which results in chemical dissolution of minerals from the tooth when the $\mathrm{pH}$ of the oral environment falls below 5.5 [1]. Dental erosion is increasingly recognised as a condition affecting the younger age groups, and in previous studies on the primary dentition a high prevalence of up to $82 \%$ has been reported [2,3]. For example, Kazoullis et al. [3] reported an erosion prevalence of $78 \%$ in Australian children aged 5- to 15 -year-old.

The erosion process is initiated by intrinsic or extrinsic acids without bacterial involvement. The repeated acidic exposures lead to a demineralisation cycle, which can subsequently result in severe loss of tooth structure and compromise the aesthetics and functions of the oral cavity $[1,4,5]$. Extrinsic factors that contribute to dental erosion include diet, medications, environment, and lifestyle behaviours $[1,4]$. Dietary factors are one of the important extrinsic risks, with carbonated soft drinks and fruit juices being most significant [6,7]. The products contain added acids which improve the palatability and organoleptic properties of the drink, and are becoming a concern in current society [8]. In addition, paediatric medications also often contain various acids to improve intake compliance [9]. The main acids added to the drinks include citric, ascorbic, and phosphoric acids [8]. These acids decrease the $\mathrm{pH}$ and increase the titratable acidity (TA), and therefore, enhance the erosive potential [8]. Although there are several previous studies regarding the erosivity of commercial drinks $[8,10]$, only a handful of studies are available on paediatric medications $[9,11,12]$.
The paediatric over-the-counter (OTC) medications are increasingly consumed by children to treat common conditions such as fever, coughs and colds, and teething [13]. Therefore, regular exposure of the dentition to the acids in the medications will increase the potential for erosion. The high acidity of common beverages has prompted investigations to reduce their erosive potential through the addition of various compounds such as fluoride, calcium, phosphate, iron, tin, and sodium hexametaphosphate. These added compounds can increase the gradient of ion concentration present in the drink compared to the tooth surface minerals [14]. These ions may also form a protective layer against loss of tooth minerals from acids, as well as increase the $\mathrm{pH}$ and decrease the TA of the acidic drink [14]. Although there have been a few studies reporting on the $\mathrm{pH}$ of paediatric drinks and a couple of investigations on the protective effects of casein phosphopeptideamorphous calcium phosphate (CPP-ACP) in reducing the erosivity of carbonated beverages, there has been no previous research on the effects of using commercially available remineralising agents directly, such as Tooth Mousse ${ }^{\oplus}$ (GC Corporation, Tokyo, Japan), on erosivity ( $\mathrm{pH}$ and TA) of paediatric medications. Therefore, the present study aimed to test the erosivity of common paediatric OTC medications and to assess the change of the erosive potential of the medications in the presence of commercial remineralising agents.

*Corresponding author: Linda Lizhu Huang, School of Dentistry, University of Queensland, 200 Turbot St Brisbane, Queensland 4000, Australia, Tel: 0435014939; E-mail: linda.huang@uqconnect.edu.au

Received May 04, 2014; Accepted June 30, 2014; Published July 02, 2014

Citation: Huang LL, Chai L, Seow WK (2014) The Erosivity Potential of Common Paediatric Over-The-Counter Medications and its Reduction by Remineralising Agents. Dentistry 4: 241. doi:10.4172/2161-1122.1000241

Copyright: $\odot 2014$ Huang LL, et al. This is an open-access article distributed under the terms of the Creative Commons Attribution License, which permits unrestricted use, distribution, and reproduction in any medium, provided the original author and source are credited. 


\section{Methods}

Twelve paediatric OTC medications and 21 commercially available paediatric beverages were purchased from the pharmacy retail outlet and the local supermarket. These items are listed in Table 1.

\section{pH and titratable acidity measurements}

The $\mathrm{pH}$ was measured at 5 minutes using a MI-413 Combination pH Electrode (Microelectrodes, Inc., New Hampshire, USA), which was calibrated at the start of every session using buffer standards of pH 4 and pH 7 (IsoLab, Wertheim, Germany). Every drink was tested with standard volume $(20 \mathrm{~mL})$ from a freshly opened bottle. Every experiment was performed in triplicate at room temperature $\left(22^{\circ} \mathrm{C}\right)$ and the mean and standard deviation obtained. Phosphate-buffered saline (PBS) was employed as the control.
The TA of each drink was assayed using a standard protocol of acid-base titration [10]. In brief, $0.1 \mathrm{M}$ sodium hydroxide $(\mathrm{NaOH})$ was progressively added to $20 \mathrm{~mL}$ of each drink until neutralisation $(\mathrm{pH}$ 7) was attained using the same electrode. The volume of $0.1 \mathrm{M} \mathrm{NaOH}$ required was recorded.

\section{pH and titratable acidity measurements of representative drinks after addition of remineralising agents}

Representative items (Table 2) were randomly selected from each category in Table 1 and were tested to examine the effects after the addition of various remineralising agents. These remineralising agents were Tooth Mousse (TM; GC Corporation, Tokyo, Japan), Tooth Mousse Plus ${ }^{\oplus}$ (TMP; GC Corporation, Tokyo, Japan), Clinpro ${ }^{\mathrm{TM}}$ (3M, Minnesota, USA), $1.23 \%$ neutral sodium fluoride (NaF), and artificial saliva (AS). To simulate intraoral conditions where there is dilution

\begin{tabular}{|c|c|c|c|c|}
\hline Number & Name & Manufacturer & $\mathrm{pH}$ mean (士SD) & TA mean $(\mathrm{mL})( \pm \mathrm{SD})$ \\
\hline \multicolumn{5}{|c|}{ Over-the-counter medications } \\
\hline 1 & Brauer natural medication teething relief & Brauer Natural Medication Pty. Ltd. & $2.7(0)$ & $5.6(0)$ \\
\hline 2 & Brauer natural medication children's cough relief & Brauer Natural Medication Pty. Ltd. & $2.7(0)$ & $5.6(0)$ \\
\hline 3 & Brauer natural medication stomach calm & Brauer Natural Medication Pty. Ltd. & $2.7(0)$ & $5.7(0.2)$ \\
\hline 4 & Brauer natural medication pain and fever relief & Brauer Natural Medication Pty. Ltd. & $2.7(0)$ & $5.6(0)$ \\
\hline 5 & Hartley's natural gripe water & L W \& S Hartley Pty. Ltd. & $5.5(0.1)$ & $1.6(0)$ \\
\hline 6 & Penta-vite multivitamins with iron & Bayer Australia Limited. & $2.6(0.1)$ & $25.1(0.6)$ \\
\hline 7 & Incremin $®$ iron mixture & Wyeth Consumer healthcare Pty. Ltd. & $4.5(0.1)$ & $6.5(0.2)$ \\
\hline 8 & Zyrtec rapid acting sugar free oral liquid banana flavor & Johnson \& Johnson Pacific Pty. Ltd. & $4.6(0)$ & $4.0(0)$ \\
\hline 9 & Dimetapp Elixir cold and allergy & Wyeth Consumer healthcare Pty. Ltd. & $2.3(0)$ & $15.7(0.2)$ \\
\hline 10 & Duro-Tuss chesty cough liquid & iNova Pharmaceuticals (Aust) Pty. Ltd. & $2.7(0)$ & $16.7(0.2)$ \\
\hline 11 & Children's Panadol (1-5yrs) & GlaxoSmithKline Consumer Healthcare & $5.0(0)$ & $0.9(0.2)$ \\
\hline 12 & Nurofen for children (1-5yrs) & Reckitt Benckiser & $4.1(0)$ & $25.9(1.4)$ \\
\hline \multicolumn{5}{|c|}{ Fruit Juices } \\
\hline 13 & Golden Circle Junior fruit drink apple and blackcurrant & Golden Circle Limited & $2.8(0.2)$ & $4.2(0.1)$ \\
\hline 14 & Golden Circle apple fruit drink & Golden Circle Limited & $2.1(0.1)$ & $13.1(0.2)$ \\
\hline 15 & Pop Tops wild berries & P\&N Beverages Australia Pty. Ltd. & $2.9(0.1)$ & $12.1(0.1)$ \\
\hline 16 & Heinz apple and cranberry fruit drink & H. J. Heinz Company Australia Limited. & $2.1(0.1)$ & $6.3(0.1)$ \\
\hline 17 & Robinson's fruit shoot juice summer fruits & Bickford's Australia Pty. Ltd. & $2.7(0)$ & $9.5(0.1)$ \\
\hline 18 & Daily Juice Company orange & Daily Juice company & $3.4(0.1)$ & $22.5(0.3)$ \\
\hline 19 & Ribena blackcurrant fruit juice syrup & GlaxoSmithKline & $2.7(0)$ & $6.6(0.1)$ \\
\hline 20 & Cottee's raspberry cordial & Schweppes Australia & $2.5(0)$ & $4.5(0.1)$ \\
\hline 21 & Cottee's lemon crush cordial & Schweppes Australia & $2.4(0.1)$ & $8.5(0.1)$ \\
\hline \multicolumn{5}{|c|}{ Carbonated drinks } \\
\hline 22 & Coca-Cola & Coca-Cola Amatil & $2.1(0)$ & $5.6(0)$ \\
\hline 23 & Kirk's Original lemonade & CCA Group & $2.4(0)$ & $7.8(0)$ \\
\hline \multicolumn{5}{|l|}{ Water } \\
\hline 24 & Mount Franklin spring water & Coca-Cola Amatil & $6.3(0.1)$ & $0.1(0)$ \\
\hline \multicolumn{5}{|c|}{ Dairy products } \\
\hline 25 & Paul's full cream milk & Pramalat Australia Ltd. & $6.6(0.1)$ & $1.3(0.2)$ \\
\hline 26 & Sanitarium So Good regular soy milk & $\begin{array}{l}\text { Australasian Health and Nutrition Association } \\
\text { Limited. }\end{array}$ & $7.3(0.1)$ & $0.4(0)$ * \\
\hline 27 & Nestlé Kids yoghurt strawberry squeeze & Nestlé Oceania & $3.6(0.1)$ & $19.9(0.2)$ \\
\hline 28 & Calci Yum milk with chocolate flavour & Fonterra Brands (AUST) Pty. Ltd. & $6.6(0)$ & $0.9(0.2)$ \\
\hline \multicolumn{5}{|c|}{ Baby formulas } \\
\hline 29 & Karicare gold plus & Nutricia Australia Pty. Ltd. & $6.8(0)$ & $0.3(0.1)$ \\
\hline 30 & S-26 gold toddler & Wyeth Australia Pty. Ltd. & $6.8(0.1)$ & $0.5(0.3)$ \\
\hline 31 & S-26 AR for babies with reflux and regurgitation & Wyeth Australia Pty. Ltd. & $6.5(0.1)$ & $0.5(0.2)$ \\
\hline 32 & S-26 SOY for babies who need to avoid dairy & Wyeth Australia Pty. Ltd. & $6.4(0.1)$ & $0.5(0.1)$ \\
\hline 33 & S-26 LF for lactose intolerant babies & Wyeth Australia Pty. Ltd. & $7.4(0)$ & $0.2(0.6)$ * \\
\hline
\end{tabular}

Table 1: The $\mathrm{pH}$ and titratable acidity (TA) of paediatric over-the-counter medicines and commercially available drinks. 
Citation: Huang LL, Chai L, Seow WK (2014) The Erosivity Potential of Common Paediatric Over-The-Counter Medications and its Reduction by Remineralising Agents. Dentistry 4: 241. doi:10.4172/2161-1122.1000241

\begin{tabular}{|c|c|c|}
\hline Drink & Manufacturer & Ingredients \\
\hline Coca-Cola & Coca-Cola Amatil & Carbonated purified water, cane sugar, colour (caramel 150d) food acid (338), flavour, caffeine \\
\hline $\begin{array}{l}\text { Cottee's Lemon Crush Double } \\
\text { Concentrate }\end{array}$ & Schweppes Australia & $\begin{array}{l}\text { Sugar, water, lemon juice from concentrate }(50 \%) \text {, natural flavours, food acid (citric acid), thickener (sodium } \\
\text { carboxymethylcellulose), sweetener (sucralose), preservatives (sodium metabisulphite, sodium benzoate), } \\
\text { natural colour (lutein) }\end{array}$ \\
\hline Daily Juice Company Orange & Daily Juice Company & Orange Juice and reconstituted orange juice $(99.9 \%)$, preservative (202), natural flavours, vitamin C \\
\hline Pop Tops Wild Berries & $\begin{array}{ll}\text { P\&N } & \text { Beverages } \\
\text { Australia Pty. Ltd. }\end{array}$ & $\begin{array}{l}\text { Water, reconstituted juices (apple } 32.5 \% \text {, raspberry } 1 \% \text {, cranberry } 1 \% \text {, blueberry } 0.5 \% \text { ), sugar, food acid } \\
\text { (citric acid), preservatives }(211,223) \text {, flavour, colour (carmoisine) }\end{array}$ \\
\hline Penta-vite Multivitamins with Iron & Bayer Australia Ltd. & Vit B1, B2, B3, B6, C, D3, iron, artificial sweeteners, flavouring, sorbitol, xanthum gum, water. \\
\hline Paul's Full Cream Milk & Pramalat Australia Ltd. & Whole milk \\
\hline S-26 Gold Toddler & Wyeth Australia Pty. Ltd. & $\begin{array}{l}\text { Non-fat milk powder, lactose, vegetable oils (including soybean), whey protein concentrate, maltodextrin, } \\
\text { emulsifier (soy lecithin), ethyl vanillin, long chain polyunsaturated fatty acids from single-cell sources } \\
\text { [arachidonic acid-AA, docosahexaenoic acid - DHA], antioxidants (mixed tocopherols concentrate, ascorbyl } \\
\text { palmitate), lutein, minerals and vitamins }\end{array}$ \\
\hline Spring Water & Coca-Cola Amatil & Australian Spring Water \\
\hline
\end{tabular}

Table 2: Representative drinks used for the experiment and their ingredients.

of the applied paste by saliva, TM, TMP, and Clinpro ${ }^{\mathrm{TM}}$ were applied as slurries [ $1 \mathrm{~g}$ of paste to $10 \mathrm{~mL}$ distilled water (i.e. $10 \% \mathrm{wt} / \mathrm{vol})$ ]. Neutral $\mathrm{NaF}$ solution was applied as a $1.23 \% \mathrm{wt} / \mathrm{vol}$ solution. TM, TMP, Clinpro $^{\mathrm{TM}}, \mathrm{NaF}$, and AS were individually added to each representative drink at the following concentrations vol/ $\mathrm{vol}(0.01,0.1,1,5,10,20,30$, $40,50,60,70,80,90 \%)$. The $\mathrm{pH}$ and TA were recorded after 5 minutes. To ascertain whether the effects were due to dilution, test with control (PBS solutions) was performed. All experiments were performed in triplicate.

\section{Statistical analysis}

The student's t-test (two-tailed), Dunnett multiple comparisons test, and one-way ANOVA were performed on Instat 3 (GraphPad Software, California, USA). An alpha value of 0.05 was employed.

\section{Results}

\section{$\mathrm{pH}$ and titratable acidity of beverages}

As shown in Table 1, paediatric OTC medications exhibited $\mathrm{pH}$ values between 2.3 and 5.5. Similarly, the fruit juices and carbonated drinks had low $\mathrm{pH}$ values between ranged between $\mathrm{pH} 2.1$ to $\mathrm{pH} 3.4$ (Table 1). In contrast, water, dairy products, and paediatric formulas (excluding a yogurt strawberry squeeze which had $\mathrm{pH}$ 3.6) exhibited near-neutral $\mathrm{pH}$ (Table 1).

As demonstrated in Table 1, a standard volume of $20 \mathrm{~mL}$ of paediatric OTC medications exhibited a wide range of TA between 0.9 $\mathrm{mL}$ to $25.9 \mathrm{~mL}$ of $0.1 \mathrm{M} \mathrm{NaOH}$ (Table 1 ). This wide titratable acidity range was comparable to fruit juices and carbonated drinks, which exhibited values between $4.2 \mathrm{~mL}$ to $22.5 \mathrm{~mL}$ of $0.1 \mathrm{M} \mathrm{NaOH}$ (Table 1). Most fruit drinks had higher TA compared to cordials and carbonated drinks (Table 1). In contrast, water, dairy products, and baby formulas exhibited low TA (excluding a yogurt strawberry squeeze) of $<1.3$ $\mathrm{mL}$ of $0.1 \mathrm{M} \mathrm{NaOH}$ or $0.1 \mathrm{M} \mathrm{HCl}$ (Table 1 ). The yogurt strawberry squeeze exhibited a relatively high TA of $19.9 \mathrm{~mL}$ (Table 1). In contrast, a soymilk product was basic and required $0.4 \mathrm{~mL}$ of $0.1 \mathrm{M}$ hydrochloric acid $(\mathrm{HCl})$ to neutralise the alkalinity (Table 2).

The various remineralising agents and controls were found to exhibit near neutral $\mathrm{pH}$ between $6.8 \pm 0.1$ and $7.6 \pm 0.1$, and required $\leq 0.1 \mathrm{~mL}$ of 0.1 $\mathrm{M} \mathrm{NaOH}$ or $0.1 \mathrm{M} \mathrm{HCl}$ to neutralise the solutions to $\mathrm{pH} 7$.

\section{$\mathrm{pH}$ and titratable acidity of representative drinks after addition of remineralising agents}

Figures $1 \mathrm{~A}-1 \mathrm{C}$ show the $\mathrm{pH}$ of a paediatric OTC medication (multivitamin supplement), commercial acidic drink (lemon
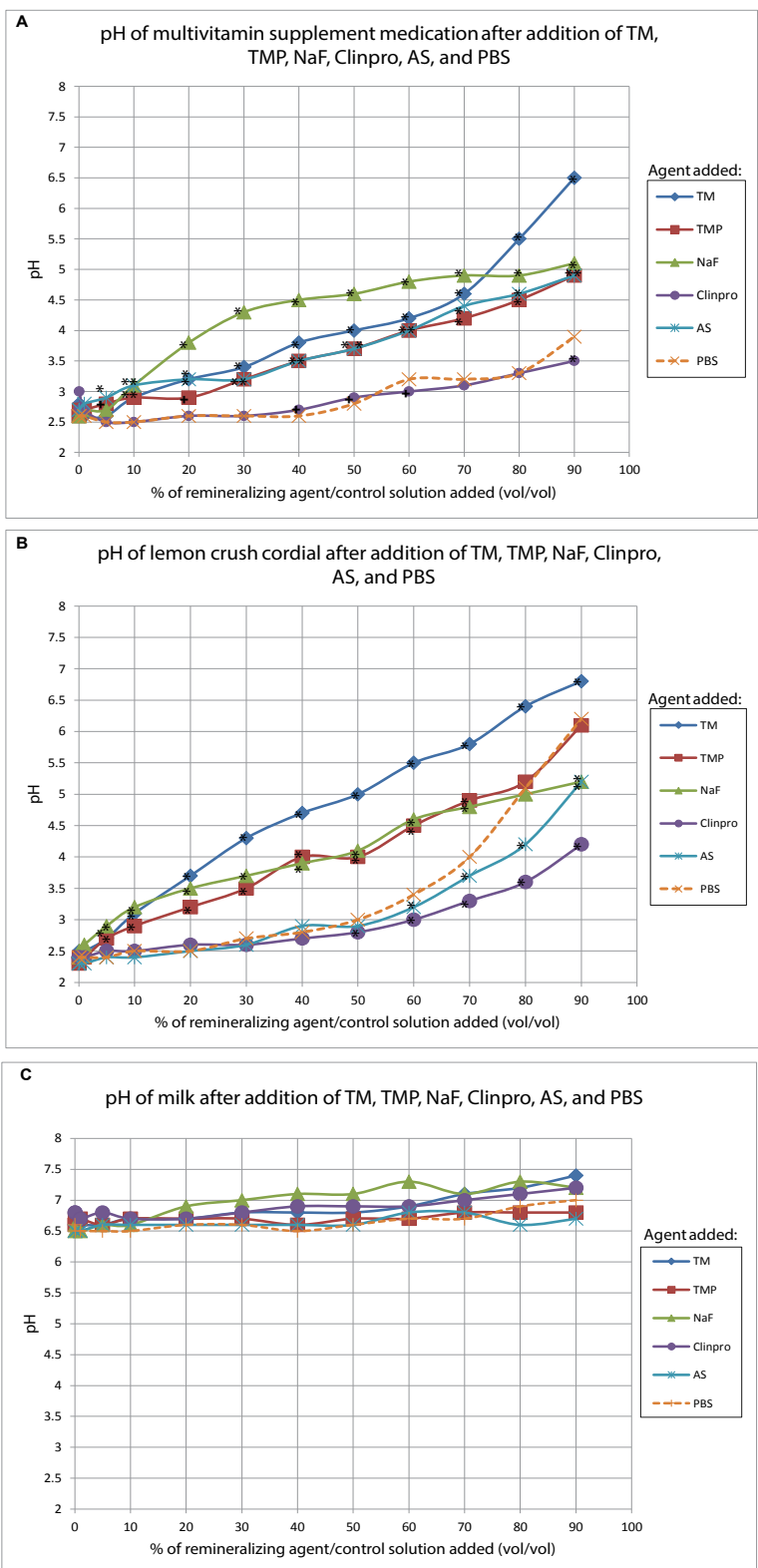

Figure 1A-C: $\mathrm{pH}$ of multivitamin supplement medication, lemon crush cordial, and milk after addition of Tooth Mousse $₫$ (TM), Tooth Mousse Plus ${ }^{\circledR}$ (TMP), sodium fluoride (NaF), Clinpro ${ }^{\mathrm{TM}}$, artificial saliva (AS), and phosphate-buffered saline (PBS) at various \% ( $\mathrm{vol} / \mathrm{vol})$ concentrations 
crush cordial), and a near-neutral drink (milk) after addition of remineralising agents and control. In all cases, the $\mathrm{pH}$ increased with increasing concentrations of added remineralising agents (Figure 1A and $1 \mathrm{~B}$ ). In all the tested acidic drinks, the addition of equal volumes of TM, TMP, neutral $\mathrm{NaF}$, and AS produced significantly higher $\mathrm{pH}$ than Clinpro ${ }^{\mathrm{TM}}$ or PBS $(\mathrm{p}<0.001)$ (Figure $1 \mathrm{~A}$ and $\left.1 \mathrm{~B}\right)$. The addition of Clinpro $^{\mathrm{TM}}$ to the acidic drinks had significantly lower $\mathrm{pH}$ compared to other remineralising agents $(\mathrm{p}<0.001)$ and similar values to the control (Figure 1A and 1B). The remineralising agent that required the smallest concentration to achieve the critical pH 5.5 in the acidic drinks was TM (Figure 1B). In addition, the critical pH 5.5 was also achieved by the addition of TM, TMP, and PBS, but not NaF, AS, or Clinpro ${ }^{\mathrm{TM}}$ in the acidic drinks (Figure 1A and $1 \mathrm{~B}$ ). Although the volume of TM slurry required to reach this critical $\mathrm{pH}$ in the multivitamin supplement medication appeared relatively large, the final concentration (\%) of TM present in the commercial paste form was only $8 \%$ (wt/vol) (Table 3 ). As shown in Figure 1C, the $\mathrm{pH}$ of milk remained near-neutral after the addition of remineralising agents or control.

The TA of a standard volume of $2 \mathrm{~mL}$ of the representative drinks with the addition of remineralising agents demonstrated a trend of decreasing volume of $0.1 \mathrm{M} \mathrm{NaOH}$ with increasing concentration of remineralising agents (Figure $2 \mathrm{~A}$ and $2 \mathrm{~B}$ ). The TAs of multivitamin supplement medication with the added remineralising agents required large volumes of $\mathrm{NaOH}$ to neutralise (initially $>2.5 \mathrm{~mL}$ of $0.1 \mathrm{M} \mathrm{NaOH}$ ) compared to the lemon crush cordial (initially $>0.8 \mathrm{~mL}$ of $0.1 \mathrm{M} \mathrm{NaOH}$ ) (Figure 2A and 2B). In the acidic drinks, the addition of TM, TMP, NaF and AS resulted in lower TAs compared to Clinpro $^{\mathrm{TM}}$ or PBS addition (all $\mathrm{p}<0.001-\mathrm{p}<0.05$ ) (Figure $2 \mathrm{~A}$ and $2 \mathrm{~B}$ ). In addition, the addition of Clinpro $^{\mathrm{TM}}$ and PBS were found to have comparable TA $(\mathrm{p}=0.46)$ (Figure 2A and 2B). Furthermore, the TAs of milk after addition of remineralising agents or control remained within a very small range (0.1-0.2 mL) (Figure 2C).

\section{Discussion}

Dental erosion is a growing concern in children as the condition often remains undetected until quite severe signs and symptoms develop [1]. It is generally thought that the destructive process begins when $\mathrm{pH}$ of the oral cavity falls below 5.5 due to the presence of acids [6]. However, it is now emerging that critical $\mathrm{pH}$ may involve a range rather than a single constant as previously thought [15].

As most children are unable to swallow medications in a simple tablet form, alternative formulations such as chewable tablets,

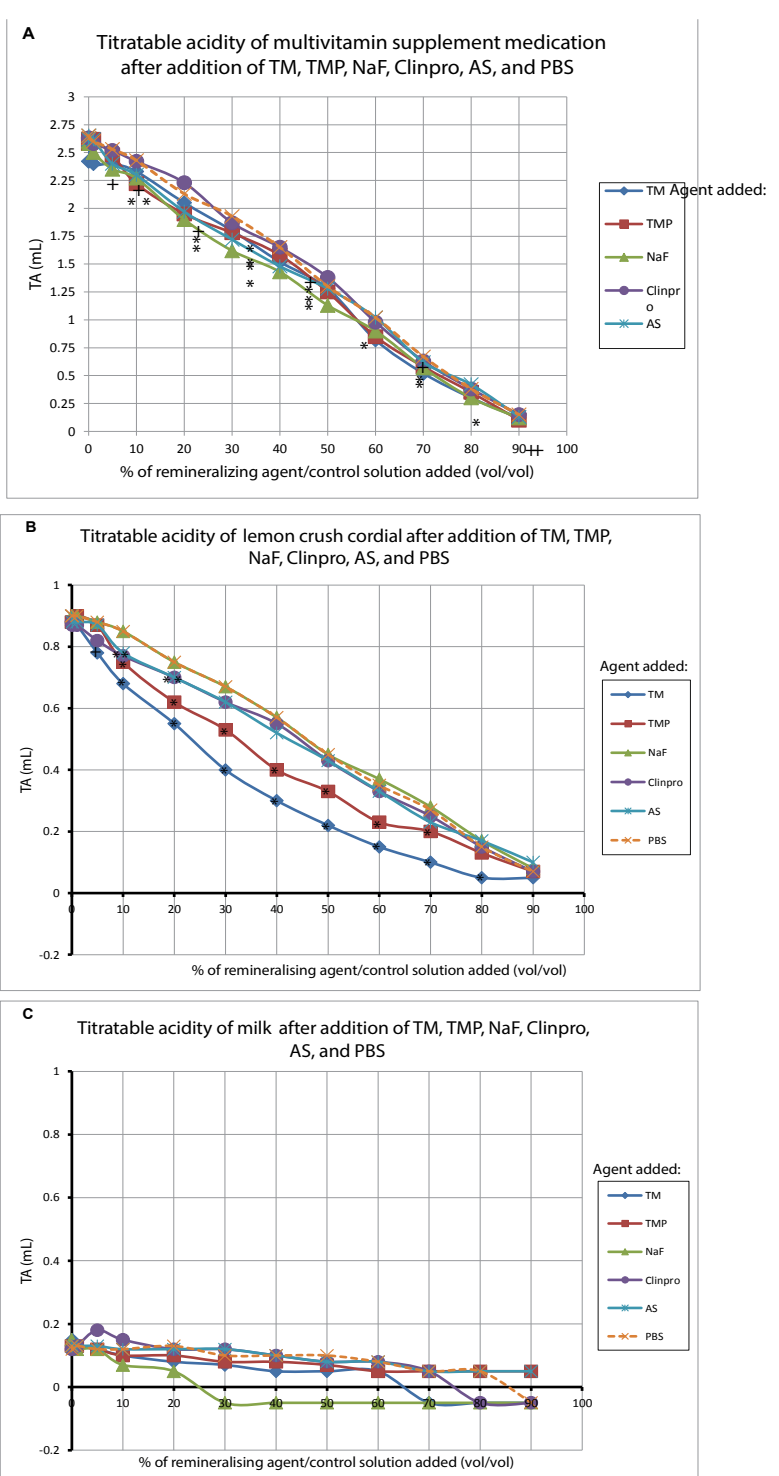

Figure 2A-C: Titratable acidity of multivitamin supplement medication, lemon crush cordial, and milk after addition of Tooth Mousse $\circledast$ (TM), Tooth Mousse Plus ${ }^{\circledR}$ (TMP), sodium fluoride (NaF), Clinpro ${ }^{T M}$, artificial saliva (AS), and phosphate-buffered saline (PBS) at various \% (vol/vol) concentrations.

\begin{tabular}{|c|c|c|c|}
\hline $\begin{array}{l}\%(\mathrm{vol} / \mathrm{vol}) \text { remineralising agent/ } \\
\text { control solution added to drink }\end{array}$ & $\begin{array}{c}\text { Actual \% (wt/vol) of paste for Tooth } \\
\text { Mousse } \AA / \text { Tooth Mousse Plus } ₫ / \\
\text { Clinpro }^{\text {TM }}\end{array}$ & $\begin{array}{l}\text { Actual } \%(w t / v o l) \text { of original solution } \\
\text { of } 1.23 \% \text { neutral sodium fluoride }\end{array}$ & $\begin{array}{c}\text { Actual \% (vol/vol) of original solution } \\
\text { of artificial saliva/ phosphate buffered } \\
\text { saline }\end{array}$ \\
\hline 1 & 0.1 & 0.01 & 1 \\
\hline 5 & 0.5 & 0.06 & 5 \\
\hline 10 & 1 & 0.12 & 10 \\
\hline 20 & 2 & 0.25 & 20 \\
\hline 30 & 3 & 0.37 & 30 \\
\hline 40 & 4 & 0.49 & 40 \\
\hline 50 & 5 & 0.62 & 50 \\
\hline 60 & 6 & 0.74 & 60 \\
\hline 70 & 7 & 0.86 & 70 \\
\hline 80 & 8 & 0.98 & 80 \\
\hline 90 & 9 & 1.11 & 90 \\
\hline 100 & 10 & 1.23 & 100 \\
\hline
\end{tabular}

Table 3: Percentages of paste in mixtures for $\mathrm{pH}$ and titratable acidity determinations. 
effervescent tablets, and liquid medications have been employed $[9,12]$. These formulations may have high erosive potential with Maguire et al. [9] study reported over half of the British medications surveyed having $\mathrm{pH}$ values significantly below the critical $\mathrm{pH}$. Furthermore, this erosive potential is particularly harmful when used by children suffering xerostomia or taken on a regular basis and/or at night in the treatment of a chronic condition $[9,11,16,17]$.

Both salivary flow and content play important roles in the protection of tooth structure from the acids [18]. Healthy saliva contains many types of bicarbonate, particularly during stimulated salivary flow, which aid in the neutralisation of the acidic content [18]. In addition, saliva also provides the protein required for formation of the salivary pellicle that act as a physical barrier against erosion and act as a reservoir of ions for remineralisation [18]. When there is a reduction in salivary flow and content, there is prolonged salivary clearance time which increases the risk for erosion $[6,19]$. This is worse in children as they generally exhibit reduced salivary flow and slower salivary clearance ability compared to adults, which may also account for the higher prevalence of erosion in the primary teeth [20]. Furthemore, consumption of drinks at bedtime or use of a feeding bottle has also been linked with increased prevalence of erosion [7]. This is due to prolonged exposure to the acids from the drinks with the continuous flow and is further compounded by the compromised salivary parameters at night $[1,21]$. Therefore, medications given between meals and during the night when saliva is at its lowest may play a significant role in the formation of erosion [11].

The two leading beverages linked to the etiology of dental erosion are carbonated drinks and fruit juices [22]. The high levels of consumption of acidic drinks are likely to be associated with the alarming prevalence of erosion among the pre-school children reported in the studies of Millward et al. [23] and Al-Malik et al. [24]. The $\mathrm{pH}$ of the carbonated drinks and fruit-based drinks examined in the present study ranged between 2.1-2.4 and 2.1-3.4, respectively, which is consistent with previous studies [6-8,10,25-28]. Interestingly, all paediatric OTC medications examined in the present study also exhibited low $\mathrm{pH}$ in a similar range between 2.3-4.6. This $\mathrm{pH}$ range of the paediatric OTC medications is in accordance with the handful of previously papers published on prescription medications $[9,16,17,29]$. Therefore, paediatric OTC medications have $\mathrm{pH}$ values below the critical $\mathrm{pH}$ for demineralisation to occur, similar to the carbonated and fruit-based drinks.

The variations in $\mathrm{pH}$ and $\mathrm{TA}$ are probably attributed to the various types and quantity of acids present in the paediatric OTC medications and commercial drinks. These acids include ascorbic, lactic, malic, tartaric, sodium citrate, phosphoric, citric, and carbonic acids, and are often added to improve palatability and shelf life $[8,10]$. The large amounts of citric and other organic acids present in the multivitamin supplement medication may explain in part the resistance to $\mathrm{pH}$ increase and TA reduction in the current study. Citric acid is often added to carbonated drinks and medications to improve palatability and has a prolonged clearance rate by saliva. Citric acid has $3 \mathrm{pKa}$ values of 3.1, 4.8, and 6.4, and therefore, can act as a buffer over a range of $\mathrm{pH}$ values $[8,29]$. When exposed to an alkaline environment, citric acid also acts as a calciumchelating agent which can destroy the hydroxyapatite crystals, therefore, compounding its erosive potential $[8,9,29]$. This was demonstrated in the study of Babu et al. [11] which examined the $\mathrm{pH}$ of 8 medications ranging from 6.05 (salbutamol) to 6.77 (paracetamol) and its effects on primary teeth. Despite the medications exhibiting $\mathrm{pH}$ values above the critical $\mathrm{pH} 5.5$, irregular pit-like lesions appeared on enamel surfaces after 1, 10 minutes, and 8 hours immersion under scanning electron microscopy, suggesting the destruction of enamel from chelative mechanisms [29]. Therefore, $\mathrm{pH}$ and TA are not the only parameters in determining the erosive potential [15,29]. Furthermore, different concentrations of active ingredients in medications may indirectly affect the $\mathrm{pH}$ and TA due to the different levels of acids added to mask the taste of the active ingredients [9]. This was demonstrated in Maguire et al. [9] study which assessed medications with the same active ingredient, but with varying concentrations of the active ingredient. Maguire et al. [9] showed that relatively high-strength medication (i.e. higher concentration of the active ingredient) had the lower $\mathrm{pH}(5.53 \pm 1.51)$ and higher TA $(0.166 \mathrm{mmol}$ $\pm 0.105)$ compared to the corresponding low-strength medication (i.e. lower concentration of the same active ingredient; $5.73 \pm 1.42$ and $0.121 \mathrm{mmol} \pm 0.091$, respectively). The high-strength medication which had a higher concentration of the active ingredient required more citric acid to mask the taste, and therefore, resulted in the relatively lower $\mathrm{pH}$ and higher TA values. This result is also in agreement with the study by Arora et al. [12].

Manufacturers have attempted to add agents to decrease the erosive potential of the drinks, as all acids cannot be removed for taste deterioration. This parameter that changes the erosive potential works through the principle of mineral concentration gradient between the drink and the tooth surface $[14,15]$. However, these attempts have been largely unsuccessful due to unacceptable changes in palatability resulting from the addition of the agents [14]. In addition, this may not be acceptable in medications due to interaction of the compounds with the active ingredient, and therefore, potentially alter the mechanism of action of the medication itself [13]. An alternative option to reducing the effects of the acids on the teeth would be topical application of the remineralising agents after intake of acidic drinks [1].

Nevertheless, the present study tested the effects of topical agents on the $\mathrm{pH}$ and $\mathrm{TA}$ of the various medication and commercially available drinks. The addition of TM,TMP, neutral NaF, and AS reduced the erosive parameters significantly compared to the control (PBS) by increasing $\mathrm{pH}$ and decreasing TA. Previous in vitro studies on acidic drinks also reported similar $\mathrm{pH}$ and TA changes after addition of the active compound in TM, CPP-ACP [19,30]. In the study of Manton et al. [19], the addition of $0.2 \%$ CPP-ACP to acidic drinks showed that a slight increase in $\mathrm{pH}$ ( 0.5 units) was associated with a significant reduction in erosive potential. This reduction in erosive potential on permanent molars under scanning electron microscopy was similar to the control, deionised distilled water [19]. These changes can be explained through the increase in calcium and phosphate ions released from the casein phosphopeptide when CPP-ACP is introduced into an acidic environment [30]. This result is in agreement with study by Dawes [15], which suggests an inverse proportion relationship between $\mathrm{pH}$ and calcium and phosphate concentration. CPP-ACP consists of a biologically active peptide, casein phosphopeptide that holds and stabilises calcium and phosphate ions in a bioavailable form, and prevents precipitation [14]. These ions become available at the tooth surface when the $\mathrm{pH}$ drops, so that demineralisation is inhibited [14].

In contrast, the present study demonstrated that the addition of Clinpro $^{\mathrm{TM}}$ resulted in no significant changes in $\mathrm{pH}$ and TA compared to the control. Clinpro ${ }^{\mathrm{TM}}$ contains fluoride and a functionalised tricalcium phosphate formulation with sodium lauryl sulphate that is able to deliver calcium and phosphate to remineralise a tooth surface when activated by saliva at neutral or alkaline $\mathrm{pH}$ [31]. It is speculated that addition of Clinpro ${ }^{\mathrm{TM}}$ to the acidic drinks did not result in significant effects on $\mathrm{pH}$ or TA in the present study as saliva was absent and the environment that the Clinpro ${ }^{\mathrm{TM}}$ was introduced to was highly acidic. 
Citation: Huang LL, Chai L, Seow WK (2014) The Erosivity Potential of Common Paediatric Over-The-Counter Medications and its Reduction by Remineralising Agents. Dentistry 4: 241. doi:10.4172/2161-1122.1000241

Lastly, the medications contain acids as well as cariogenic sugars which may also induce early childhood caries (ECC) [1]. Therefore, medications exhibit common dietary risk factors for both dental erosion and ECC. Higher levels of Streptococcus mutans have been reported in erosion affected individuals and in children suffering gastroesophageal reflux disease (a risk factor for erosion) [32]. It is speculated that the acidic environment may encourage Streptococcus mutans growth as they are acidophilic, and therefore, increasing the risk for ECC. Not many studies have been undertaken to investigate the relationship between dental erosion and ECC. The studies currently available only present an association between erosion and ECC. For instance, the study of Kazoullis et al. [3] supports a strong association between severe erosion in primary dentition and ECC $(\mathrm{p}<0.001)$. Its significance is presently still under investigation.

There are limitations in in vitro studies. As discussed previously, the addition of remineralising agents can lead to unacceptable changes in palatability of drinks and may not be acceptable in medications due to the interaction of the agent with the active ingredient $[13,14]$. Caution should also be taken in the interpretation of in vitro results, as the protective effects of biological factors (e.g. saliva flow rate, buffering capacity, and mineral content, and salivary pellicle and orofacial musculature activity) were not included in the present study. Therefore, it is likely that the in vitro results reported in this study overestimate the effects compared to an in vivo model $[7,10,21,30]$. Nevertheless, the knowledge on the erosivity of paediatric OTC medications will alert the dental profession and educate consumers, as well as manufacturers on the possible damaging potential of these medications [26].

\section{Conclusions}

In conclusion, the present study demonstrates that paediatric overthe-counter medications have erosive potential comparable to fruit drinks and carbonated drinks. It also demonstrates that commercially available remineralising products, Tooth Mousse ${ }^{\oplus}$, Tooth Mousse Plus ${ }^{\oplus}$, $1.23 \%$ neutral sodium fluoride, and artificial saliva have the potential to reduce the erosivity of paediatric over-the-counter medications, as well as carbonated drinks and fruit drinks consumed by children. Knowledge of the erosivity of paediatric over-the-counter medications will alert the dental profession to their damaging potential and help provide advice to parents of the children regarding the pathogenesis and prevention of erosion.

\section{References}

1. Taji S, Seow WK (2010) A literature review of dental erosion in children. Aust Dent J 55: 358-367.

2. Al-Majed I, Maguire A, Murray JJ (2002) Risk factors for dental erosion in 5-6 year old and 12-14 year old boys in Saudi Arabia. Community Dent Oral Epidemiol 30: 38-46

3. Kazoullis S, Seow WK, Holcombe T, Newman B, Ford D (2007) Common dental conditions associated with dental erosion in schoolchildren in Australia. Pediatr Dent 29: 33-39.

4. Johansson AK, Omar R, Carlsson GE, Johansson A (2012) Dental erosion and its growing importance in clinical practice: from past to present. Int J Dent 2012: 632907.

5. Wang X, Lussi A (2010) Assessment and management of dental erosion. Dent Clin North Am 54: 565-578.

6. Seow WK, Thong KM (2005) Erosive effects of common beverages on extracted premolar teeth. Aust Dent J 50: 173-178.

7. Lussi A, Kohler N, Zero D, Schaffner M, Megert B (2000) A comparison of the erosive potential of different beverages in primary and permanent teeth using an in vitro model. Eur J Oral Sci 108: 110-114.

8. Cochrane NJ, Cai F, Yuan Y, Reynolds EC (2009) Erosive potential of beverages sold in Australian schools. Aust Dent J 54: 238-244.
9. Maguire A, Baqir W, Nunn JH (2007) Are sugars-free medicines more erosive than sugars-containing medicines? An in vitro study of paediatric medicines with prolonged oral clearance used regularly and long-term by children. Int $J$ Paediatr Dent 17: 231-238

10. Hunter L, Patel S, Rees J (2009) The in vitro erosive potential of a range of baby drinks. Int J Paediatr Dent 19: 325-329.

11. Babu KL, Rai K, Hedge AM (2008) Pediatric liquid medicaments - do they erode the teeth surface? An in vitro study: Part I. J Clin Pediatr Dent 32: 189-194.

12. Arora R, Mukherjee U, Arora V (2012) Erosive potential of sugar free and sugar containing pediatric medicines given regularly and long term to children. Indian J Pediatr 79: 759-763.

13. Paul IM (2012) Advances in pediatric pharmacology, therapeutics, and toxicology. Adv Pediatr 59: 27-45.

14. Lussi A (2009) Dental erosion - novel remineralizing agents in prevention or repair. Adv Dent Res 21: 13-16.

15. Dawes $\mathrm{C}$ (2003) What is the critical $\mathrm{pH}$ and why does a tooth dissolve in acid? J Can Dent Assoc 69: 722-724.

16. Nunn JH, Ng SKF, Sharkey I, Coulthard M (2001) The dental implications of chronic use of acidic medicines in medically compromised children. Pharm World Sci 23: 118-119.

17. Neves BG, Farah A, Lucas E, de Sousa VP, Maia LC (2010) Are paediatric medicines risk factors for dental caries and dental erosion? Community Dent Health 27: 46-51.

18. Almeida e Silva JS, Baratieri LN, Araujo E, Widmer N (2011) Dental erosion: understanding this pervasive condition. J Esthet Restor Dent 23: 205-216.

19. Manton DJ, Cai F, Yuan Y, Walker GD, Cochrane NJ, et al. (2010) Effect of casein phosphopeptide-amorphous calcium phosphate added to acidic beverages on enamel erosion in vitro. Aust Dent J 55: 275-279.

20. Crossner CG, Hase JC, Birkhed D (1991) Oral sugar clearance in children compared with adults. Caries Res 25: 201-206.

21. Johansson AK, Sorvari R, Birkhed D, Meurman JH (2001) Dental erosion in deciduous teeth - an in vivo and in vitro study. J Dent 29: 333-340.

22. Dugmore CR, Rock WP (2004) A multifactorial analysis of factors associated with dental erosion. Br Dent J 196: 283-286.

23. Millward A, Shaw L, Smith A (1994) Dental erosion in four-year-old children from differing socioeconomic backgrounds. ASDC J Dent Child 61: 263-266.

24. Al-Malik MI, Holt RD, Bedi R (2002) Erosion, caries and rampant caries in preschool children in Jeddah, Saudi Arabia. Community Dent Oral Epidemio 30: $16-23$

25. Singh S, Jindal R (2010) Evaluating the buffering capacity of various soft drinks, fruit juices and tea. J Conserv Dent 13: 129-131.

26. Brown CJ, Smith GAY, Shaw L, Parry J, Smith AJ (2007) The erosive potential of flavoured sparkling water drinks. Int J Paediatr Dent 17: 86-91.

27. Cairns AM, Watson M, Creanor SL, Foye RH (2002) The pH and titratable acidity of a range of diluting drinks and their potential effect on dental erosion. J Dent 30: 313-317.

28. Lussi A, Megert B, Shellis RP, Wang X (2012) Analysis of the erosive effect of different dietary substances and medications. Br J Nutr 107: 252-262.

29. Babu KL, Rai K, Hegde AM (2008) PH of medicated syrups - does it really matter? An in-vitro study: Part-II. J Clin Pediatr Dent 33: 137-142.

30. Ramalingam L, Messer LB, Reynolds EC (2005)Adding casein phosphopeptideamorphous calcium phosphate to sports drinks to eliminate in vitro erosion. Pediatr Dent 27: 61-67.

31. Walsh LJ (2012) Strategies for remineralization. Wiley-Blackwell.

32. O'Sullivan EA, Curzon MEJ (2000) Salivary factors affecting dental erosion in children. Caries Res 34:82-87. 